\title{
Contribuições da Genealogia de Michel Foucault à Bioética: aspectos metodológicos para o estudo de dispositivos do biopoder
}

\author{
Contributions of the Michel Foucault's genealogy to Bioethics: methodological \\ aspects for the study of bio-power devices \\ Fernando Hellmann ${ }^{1}$ \\ Marta Verdi ${ }^{2}$
}

\begin{abstract}
Resumo
Alguns bioeticistas têm utilizado os aportes teóricos e metodológicos das obras de Michel Foucault em seus estudos. Contudo, há carência de trabalhos em bioética sobre os aspectos metodológicos da genealogia de Foucault. $\mathrm{O}$ artigo tem por objetivo exibir os referidos aspectos como contribuição à bioética, sobretudo quanto ao estudo de dispositivos do biopoder. Para tanto, conceitos foucaultianos são apresentados, bem como as precauções metodológicas a propósito da genealogia. Inicia-se por uma contextualização das obras do autor, problematiza-se a passagem da arqueologia à genealogia, mostram-se peculiaridades da genealogia como método para a análise do exercício do poder e, após, discorre-se acerca da disciplina e da biopolítica como formas de exercício do poder sobre a vida (biopoder). Por fim, um exemplo de análise genealógica de dispositivos do biopoder é apresentado: trata-se da análise genealógica de preceitos éticos para pesquisa envolvendo seres humanos expressos na Declaração de Helsinque no quadro da biopolítica.
\end{abstract}

Palavras-chave: Foucault. Genealogia. Biopoder. Biopolítica. Bioética.

\begin{abstract}
Some bioethicist has used the theoretical and methodological contributions of the Michel Foucault work in his studies. However, there are few bioethical studies on the methodological aspects of Foucault's genealogy. The article aims to show these aspects as a contribution to bioethics, especially concerning the study of biopower devices. To do so, Foucault concepts are presented as well as the methodological precautions concerning the genealogy. It begins with a contextualization of the author's work, problematizes the passage from archeology to genealogy, displays peculiarities of genealogy as a method for analyzing the exercise of power, and after, expatiates on discipline and biopolitics as ways of exercising power over life (biopower). Finally, an example of genealogical analysis of biopower devices is presented: the genealogical analysis of ethical guidelines for research involving human subjects expressed in the Declaration of Helsinki under biopolitics scope.
\end{abstract}

Keywords: Foucault. Genealogy. Biopower. Biopolitics. Bioethics.

\footnotetext{
${ }^{1}$ Coordenador do Comitê de Ética em Pesquisa da Universidade do Sul de Santa Catarina e bolsista CAPES. E-mail: hellmann.fernando@gmail.com

${ }^{2}$ Membro do Programa de Pós-Graduação em Saúde Coletiva, Universidade Federal de Santa Catarina (UFSC). E-mail: marverdi@hotmail.com
}

Esta obra foi licenciada com uma Licença Creative Commons - Atribuição 3.0 Não Adaptada 


\section{Introdução}

Encontra-se no campo da bioética uma variedade metodológica para analisar as dimensões morais implicadas nas ciências da vida, nas políticas públicas e no fazer humano em geral. Entre as possibilidades de contribuições à bioética, ainda relativamente pouco explorada, estão os conceitos e aportes metodológicos expostos nas obras de Michel Foucault (1926 - 1984) (GARCES GIRALDO, 2013; ASHCROFT, 2003; FINKLER et al, 2010).

Foucault tem como tema central de estudo os processos de subjetivação do homem, problematizados em uma análise filosófica, histórica e social. Os modos de subjetivação, também de objetivação e ora sujeição, são abordados pelo autor em três diferentes facetas complementares, vislumbradas no conjunto caleidoscópico de sua obra - a qual restou por ser terminada. Estes três eixos, ou melhor, estes três momentos vislumbrados nas obras de Foucault, têm sido utilizados para a análise de temas que envolvem questões de bioética.

Em um primeiro momento, o autor debruça-se sobre o estudo das disciplinas na época moderna, em especial de como elas, constituídas por um corpo de saberes, formam e formatam o indivíduo. Frank e Jones (2003) mostram que o estudo das disciplinas tal como expostas por Foucault aproxima-se das reflexões requeridas pela bioética. Em um segundo momento, Foucault desloca-se para o tema da biopolítica, ou seja, de como os sujeitos, agora no coletivo, tornaram-se corpos a serem governados por intermédio de uma modalidade específica do biopoder. Da mesma forma, bioeticistas como Lysaught (2009), Tremain (2008), Caponi (2004), Bischop e Jotterand (2006) utilizaram-se desse tema foucaultiano em seus estudos. Por fim, em novo desvio, Foucault versa a respeito do tópico da ética sob as formas de cuidado de si; os conceitos e princípios do cuidado de si (e dos outros) são apontados por Giraldo e Zuluaga (2013) como orientadores para a construção de uma Bioética do Cuidado.

Tais deslocamentos - não entendidos como abdicações do tema central - as formas de subjetivação -, mas sim como ampliações do campo analítico - permitem pensar a obra de Foucault em três principais períodos: o da arqueologia, o da genealogia e o da ética. Todos, como visto, apresentam interface com a bioética. 
Mas se, por um lado, os três momentos da obra de Foucault significam mudanças em particularidades estudadas, por outro, denota-se que o campo da análise é ampliado sem se abdicar de certos princípios e aspectos metodológicos propostos na fase anterior. Assim, tem-se que o interesse da fase arqueológica é a descrição da episteme (saber) ${ }^{3}$ - isto é, dos fenômenos que ligam os diferentes tipos de ciências, ou melhor, os diferentes discursos científicos correspondentes a uma dada época histórica (FOUCAULT, 1972). Quando do período da genealogia, o autor apresenta como objeto de descrição os dispositivos, estes vislumbrados como os operadores materiais do poder ${ }^{4}$ (FOUCAULT, 2003). Por sua vez, na fase da ética, o autor centra-se na noção de práticas $^{5}$ de cuidado de si, ou seja, do exercício da ética e da estética da existência (FOUCAULT, 2002). Como dito, entre os deslocamentos o que ocorre é a ampliação do campo de análise. Assim, a genealogia não renunciará ao estudo das formas de saber - episteme, tampouco a ética dos dispositivos de poder. O que acontece é que, como veremos, na passagem da arqueologia à genealogia as práticas não discursivas são agregadas àquelas discursivas; e, ao final, quando do estudo da ética, nota-se que a noção de prática abarcará a de dispositivo.

Ainda que as três fases conjuntas da obra de Foucault possibilitem o estudo ampliado do sujeito imerso em um campo de saberes e poderes produtores de subjetividades e objetivações, ao que se pese o presente artigo, o recorte deverá ser feito. Assim, o objetivo deste ensaio será mostrar, como proposta metodológica em bioética, os aspectos metodológicos da genealogia em Foucault para a análise de dispositivos do biopoder. É na fase genealógica que aqui nos interessamos, ainda que seja necessário, como veremos, abordar a fase arqueológica.

Estudos em Bioética têm operacionalizado as categorias Biopolítica e Biopoder (JUNGES, 2009; LYSAUGHT, 2009; TREMAIN, 2008; CAPONI, 2004;

\footnotetext{
${ }^{3}$ Diz Foucault (1972, p. s/p): "Ce sont tous ces phénomènes de rapports entre les sciences ou entre les différents discours dans les divers secteurs scientifiques qui constituent ce que j'appelle épistémè d'une époque".

4 Entretanto, Foucault vai utilizar a palavra "dispositivos" para outros fins que não diretamente relacionados ao poder, tais como "dispositivos de saber", "dispositivos da sexualidade", "dispositivo de aliança".

${ }^{5}$ Porém, tanto "episteme" quanto "dispositivo" são, em última análise, práticas: a primeira práticas discursivas e a segunda caracteriza-se por integrar as práticas não discursivas (relações de poder) àquelas discursivas. E mais, a noção de prática em Foucault aparece desde o início de suas obras. A novidade que se tem, na última fase, é o fato de empreender a modernidade como um ethos e, portanto, o cuidado de si como prática da ética.
} 
BISCHOP, JOTTERAND, 2006; MORENO, 2014; ROMMETVEIT, 2009). Logo, utilizam-se de aspectos da genealogia de Michel Foucault. Todavia, a metodologia foucaultiana para a análise de dispositivos do biopoder não tem sido devidamente apresentada na literatura bioética.

Cabe ressaltar que Foucault não escreveu nenhuma obra metodológica que tratasse da genealogia, tal como o fez com a arqueologia - especialmente da obra "A Arqueologia do Saber" (FOUCAULT, 2007). Existem, no entanto, alguns indicadores, princípios e precauções que funcionam como ferramentas metodológicas para uma empreitada genealógica, os quais são encontrados principalmente nas obras "Vigiar e Punir" (FOUCAULT, 2011) e "Em Defesa da Sociedade" (FOUCAULT, 2000). Tais pistas metodológicas são ainda encontradas, no panorama da Biopolítica, nas obras "Segurança, Território e População" (FOUCAULT, 2008a), "Nascimento da Biopolítica" (FOUCAULT, 2008b) e "Do governo dos vivos" (FOUCAULT, 2009). A obra "Microfísica do Poder" (FOUCAULT, MACHADO, 2004) possibilita ainda reflexões que favorecem a filosofia analítica do poder.

Para atingir o objetivo proposto - expor aspectos metodológicos da genealogia em Foucault para a análise de dispositivos do biopoder - partiremos da contextualização do deslocamento da arqueologia à genealogia; na sequencia, a genealogia como proposta de análise do poder será problematizada. Após, os biopoderes - disciplina e bipolítica - são exibidos como modalidades do exercício do saber-poder. Por fim, apresenta-se uma proposta de operacionalização de conceitos e precauções metodológicas da genealogia tomando-se como ponto de partida a análise de princípios éticos expressos na Declaração de Helsinque, os quais se configuram como dispositivos do biopoder.

\section{Da Arqueologia à Genealogia: as ampliações no deslocamento}

A genealogia em Foucault é a continuidade de um caminho iniciado na fase arqueológica. A arqueologia foi, então, o primeiro passo que tornou possível o empreendimento genealógico. Dessa maneira, faz-se necessário situar aspectos da arqueologia para melhor compreender a proposta de um método genealógico. 
A descrição arqueológica propõe a abordagem da episteme, ou seja, do saber $^{6}$, a partir da materialidade dos discursos: das regularidades dos enunciados, da análise das contradições discursivas, das descrições comparativas, da instauração das transformações (rupturas). Desse modo, Foucault distancia-se de uma análise em termos de ideologia, bem como de uma história linear - descrita segundo seu progresso; ao contrário, o que interessa a Foucault é a história das próprias condições históricas e ainda de outras dimensões - econômicas, científicas, políticas, filosóficas - que permitem a construção de um determinado saber; isto é, o autor coloca em cena distintas dimensões que possibilitam a emergência de um dado discurso de saber em uma determinada época: a arqueologia, portanto, se ocupa das práticas discursivas (epistemes). Por "prática discursiva" Foucault (2007, p.133) entende um "[...] conjunto de regras anônimas, históricas, sempre determinadas no tempo e no espaço, que definiram, em uma época dada, e para uma determinada área social, econômica, geográfica ou linguística, as condições de exercício da função enunciativa"

Na medida em que Foucault passa da análise da episteme para a análise dos dispositivos, inicia-se o período no qual as práticas não discursivas entram em jogo. Trata-se da ampliação da arqueologia a caminho da genealogia, sem rupturas nem oposições de uma à outra. Esse deslocamento dá-se na introdução da análise das formas do exercício do poder: analisa-se agora o saber-poder e a relação discursividade-não-discursividade; logo, tal mudança responde a limitação da descrição arqueológica para analisar o saber como estratégias de poder:

Nessa atividade, que se pode, pois, dizer genealógica (...) trata-se, na
verdade, de fazer que intervenham saberes locais, descontínuos,
desqualificados, não legitimados, contra a instância teórica unitária que
pretenderia filtrá-los, hierarquizá-los, ordená-los em nome de um
conhecimento verdadeiro, em nome dos direitos de uma ciência que seria
possuída por alguns. As genealogias não são, portanto, retornos positivistas
a uma forma de ciência mais atenta e mais exata. As genealogias são,
muito exatamente, anticiências. Não que elas reivindiquem o direito lírico à
ignorância e ao não-saber, não que se tratasse da recusa de saber ou do
pôr em jogo, do pôr em destaque os prestígios de uma experiência
imediata, ainda não captada pelo saber. Não é disso que se trata. Trata-se
da insurreição dos saberes. Não tanto contra os conteúdos, os métodos ou
os conceitos de uma ciência, mas de uma insurreição sobretudo e acima de
tudo contra os efeitos centralizadores de poder que estão vinculados à

${ }^{6}$ Ainda que a arqueologia seja orientada principalmente à episteme, seria errôneo circunscrever a proposta arqueológica apenas ao âmbito desta. Foucault apresenta possibilidades de outras arqueologias, tais como a da sexualidade, da política (FOUCAULT, 2007).

Cad. de Pesq. Interdisc. em Ci-s. Hum-s., Florianópolis, ISSN 1984-8951

v.15, n.107, p. 158-179, ago/dez 2014 
instituição e ao funcionamento de um discurso científico organizado no interior de uma sociedade como a nossa (...). É exatamente contra os efeitos de poder próprios de um discurso considerado científico que a genealogia deve travar o combate (FOUCAULT, 2000, p.13-14).

Os efeitos de poder dos discursos dos saberes são aqueles instaurados pelos dispositivos. Como visto, dispositivos são, portanto, objetos de análise da empreitada genealógica. Foucault falará de diferentes tipos de dispositivos: de poder, de saber, de sexualidade, de aliança, de subjetividade, de verdade (CASTRO, 2009). A noção foucaultiana de dispositivo pode ser apreendida como:

1) O dispositivo é a rede de relações que podem ser estabelecidas entre
elementos heterogêneos: discursos, instituições, arquitetura, regramentos,
leis, medidas administrativas, enunciados científicos, proposições
filosóficas, morais, filantrópicas, o dito e o não dito. 2) O dispositivo
estabelece a natureza do nexo que pode existir entre esses elementos
heterogêneos. Por exemplo, o discurso pode aparecer como programa de
uma instituição, como um elemento que pode justificar ou ocultar uma
prática, ou funcionar como uma interpretação a posteriori dessa prática,
oferecer-lhe um campo novo de racionalidade. 3) trata-se de uma formação
que, em um momento dado, teve por função a responder a uma urgência. O
dispositivo tem assim uma função estratégica. [...]. 4) Além da estrutura de
elementos heterogêneos, um dispositivo se define por sua gênese. A esse
respeito, Foucault distingue dois momentos essenciais. Um primeiro
momento do predomínio do objetivo estratégico; um segundo momento, a
constituição do dispositivo propriamente dito. 5) O dispositivo, uma vez
constituído, permanece como tal na medida em que tem lugar num
processo de sobredeterminação funcional: cada efeito, positivo e negativo,
querido ou não querido, entra em ressonância com ou em contradição com
os outros e exige um reajuste. Por outro lado, encontramos também um
processo de perpétuo preenchimento (remplissement) estratégico.
(CASTRO, 2009, p. 124).

Para apreender os efeitos dos discursos dos saberes, portanto dos dispositivos que estes implicam, é necessário que a expedição genealógica analise o discurso. Dois conjuntos complementares de análise do discurso, os quais emanam princípios e regras, aparecem na obra "A Ordem do Discurso" (FOUCAULT, 1996), quais sejam: o crítico e o genealógico. Assim, regras metodológicas aparecem para um conjunto de análise.

Na postura crítica ao discurso, tem-se o princípio da inversão. Esse princípio assinala para se captar no texto, nos jogos de verdade, a inversão do significado proposto, negando-o e pondo seus significantes em evidência; nisto se observam as falsas universalizações. Sobre o princípio da inversão, Foucault (1997, p. 52) aponta que "[...] é preciso reconhecer, ao contrário, o jogo negativo de um recorte e de uma rarefação do discurso". Por conseguinte, o conhecimento genealógico do discurso 
põe em funcionamento outros três princípios metodológicos: o de descontinuidade; o de especificidade e o de exterioridade.

No princípio da descontinuidade, "os discursos devem ser tratados como práticas descontínuas, que se cruzam por vezes, mas também se ignoram ou se excluem" (FOUCAULT, 1997, p. 52). Não há, portanto, um contínuo de verdade evolutiva nos discursos, tampouco sob esses há outros discursos, silenciosos, limitados, que são reprimidos ou ainda censurados. Já o princípio de especificidade aponta para o dever de se "[...] conceber o discurso como uma violência que fazemos às coisas. [...] e é nesta prática que os acontecimentos do discurso encontram o princípio de sua regularidade" (FOUCAULT, 1997, p. 53); logo, discursos pronunciados por autores outorgados não os tornam verdades absolutas e universais. Por fim, o princípio de exterioridade aponta para distanciar-se da análise de um interior do discurso: "[...] não passar do discurso para seu núcleo interior e escondido [...] mas, a partir do próprio discurso, de sua aparição e de sua regularidade, passar às condições externas de possibilidade [...]" (FOUCAULT, 1997, p.53).

Os princípios metodológicos para uma genealogia facilitam a compreensão de possíveis caminhos para a análise dos dispositivos postos em prática pelos saberes, especialmente os científicos. Eles questionam a linearidade e a causalidade dos acontecimentos, opondo-se à pesquisa clássica da origem. A genealogia não se opõe ao método histórico tradicional; seu objetivo é
"assinalar a singularidade dos acontecimentos, fora de toda finalidade
monótona". Para a genealogia, não há essências fixas, nem leis
subjacentes, nem finalidades metafísicas. A genealogia busca
descontinuidades ali onde desenvolvimentos contínuos foram encontrados.
Ela busca recorrências e jogo ali onde progresso e seriedade foram
encontrados. Ela recorda o passado da humanidade para desmascarar os
hinos solenes do progresso. A genealogia evita a busca da profundidade.
Ela busca a superfície dos acontecimentos, os mínimos detalhes, as
menores mudanças e os contornos sutis (RABINOW, DREYFUS, 1995,
p.118).

O método genealógico põe em questionamento as verdades que se queiram universais; ele estremece a construção dos saberes-poderes que pretendem controlar a natureza histórica da verdade e do acúmulo do conhecimento. Assim, a genealogia está para a análise dos saberes inscritos em suas hierarquias de poderes próprios à ciência como um "[...] empreendimento para libertar da sujeição 
os saberes históricos, isto é, torná-los capazes de oposição e de luta contra a coerção de um discurso teórico, unitário, formal e científico". (FOUCAULT, 2004, p.172).

A genealogia, logo, é um caminho para a desconstrução de saberes e de seus dispositivos, sobretudo os de poder, que perpassam o corpo individual e o coletivo. Para Foucault (1984), existem três domínios possíveis de genealogias. Primeiro, uma ontologia histórica de nós mesmos em nossa relação com a verdade o que nos permite nos constituirmos como sujeitos do conhecimento; segundo, uma ontologia histórica de nós mesmos em nossas relações a um campo de poder - o que nos leva a nos constituirmos como indivíduos a tomar medidas sobre os outros; finalmente, uma ontologia histórica de nossa relação com a moralidade - o que nos permite constituirmo-nos como agentes éticos.

É o segundo domínio, ou seja, as nossas relações em um campo de poder, principalmente os relacionados à vida individual e coletiva - biopoder, que se ocupa a genealogia. Portanto, há que se compreender a genealogia como análise do exercício do poder.

\section{A genealogia como análise do exercício do poder}

Foucault não elaborou nenhuma sistematização teórica acerca do poder. O que o autor empreendeu foram análises, em sua maioria histórico-filosóficas, sobre o seu funcionamento. Contudo, Foucault possibilitou ferramentas para analisar o poder por meio de uma filosofia analítica (CASTRO, 2004).

Em termos genealógicos, é importante pensar o poder não como objeto, uma coisa ou um bem. Faz-se mister, ainda, reconhecer que não há, na teoria foucaultiana, aqueles que estão em posse do poder - os dominantes - e, de outro lado, os submetidos a ele - os dominados -. Antes, é necessário compreender o poder como uma prática social, construída historicamente. Logo, deve-se apreendêlo em suas diferentes formas, em suas transformações. O poder é, assim, algo que se exerce, que funciona em rede; o poder envolve táticas, estratégias, manobras (FOUCAULT, 2011).

Para Foucault (1980), ao se tentar construir uma teoria sobre o poder, será necessário que este seja sempre descrito como algo que emerge num lugar e tempo Cad. de Pesq. Interdisc. em Ci-s. Hum-s., Florianópolis, ISSN 1984-8951

v.15, n.107, p. 158-179, ago/dez 2014 
dados; a partir deste ponto é que se poderá deduzir e reconstruir sua gênese sempre em termos de relações. As especificidades da relação de poder são apresentadas pelo autor como relações entre sujeitos. Foucault falará que o termo "conduta" será o que melhor permite captar tal especificidade. O exercício do poder consiste em administrar condutas. (FOUCAULT, 2003).

Foucault (2004b) destaca cinco precauções metodológicas para uma análise genealógica do poder. A primeira delas versa acerca de captar o poder nas suas extremidades: "Não se trata de analisar as formas regulamentares e legítimas do poder em seu centro [...]. Trata-se, ao contrário, de captar o poder em suas extremidades, em suas ramificações, lá onde se torna capilar; [...]" (FOUCAULT, 2004b, p. 182). A segunda precaução será abordá-lo “[...] onde sua intenção [...] está completamente investida em práticas reais e efetivas; [...] onde ele se relaciona com aquilo que podemos chamar de objeto;" [...]" (FOUCAULT, 2004b, p. 182), o poder deve ser estudado "onde ele se implanta e produz efeitos reais (...) seria preciso procurar estudar os corpos constituídos como sujeitos pelos efeitos do poder" (FOUCAULT, 2004b, p. 183).

A terceira precaução metodológica será não tomar o poder como um fenômeno homogêneo de um indivíduo sobre outros, de um dominante sobre os dominados, de uma classe sobre outra. Logo, o poder "[...] não é algo que se possa dividir entre aqueles que possuem e o detêm exclusivamente e aqueles que lhe são submetidos [...]. O poder funciona e se exerce em rede (FOUCAULT, 2004b, p. 183)". Por sua vez, a quarta precaução será de cuidar para que a análise do poder não seja uma dedução partindo-se do centro; deve-se, ao contrário, fazer uma análise ascendente do poder:

[...] partir dos mecanismos infinitesimais que têm uma história, um caminho, técnicas e táticas e depois examinar como estes mecanismos de poder foram e ainda são investidos, colonizados, utilizados, subjugados, transformados, deslocados, desdobrados, etc., por mecanismos cada vez mais gerais e por formas de dominação global. Não é a dominação global que se pluraliza e repercute até embaixo. (FOUCAULT, 2004b, p. 184).

A quinta e última precaução metodológica apontada por Foucault versa sobre o saber como instrumento de poder. De acordo com o autor, não é na ideologia que o poder é alicerçado - é muito mais e ao mesmo tempo muito menos que isso: "São instrumentos reais de formação e de acumulação do saber: métodos 
de observação, técnicas de registros, procedimentos de inquérito e de pesquisa, aparelhos de verificação" (FOUCAULT, 2004b, p. 186). Prontamente, tem-se que o poder gera saber que circula e acaba por manter o próprio poder - "aparelhos de saber que não são construções ideológicas" (FOUCAULT, 2004b, p. 186).

Assim, ao recapitular as cinco precauções metodológicas, dirá Foucault (2004b, p. 186):

\begin{abstract}
Em vez de orientar a pesquisa sobre o poder no sentido do edifício jurídico da soberania, dos aparelhos de Estado e das ideologias que o acompanham, deve-se orientá-la para a dominação, os operadores materiais, as formas de sujeição, os usos e as conexões da sujeição pelos sistemas locais e os dispositivos estratégicos. [...] É preciso estudá-lo a partir das técnicas e táticas de dominação.
\end{abstract}

Foucault reconhece que o poder, em suas táticas de dominação, não tem apenas um papel repressivo (negativo); ele também tem outro lado, o produtivo (positivo). Se, por um lado, o poder exclui, reprime, recalca, censura, mascara, esconde, por outro, "de fato, o poder produz; ele produz real; produz domínios de objetos e rituais de verdade" (FOUCAULT, 2011, p. 161).

Por fim, outras notas para a análise do poder, a partir de Michel Foucault, são indicadas por Revel (2002), as quais propõe a exigência de se fixar e observar certos pontos importantes, ao menos cinco: (1) pensar o poder a partir das diferenciações que permitem agir sobre as ações dos outros; esse é o efeito da condição de emergência e das relações de poder (diferenças no quadro legal/jurídico quanto a status e privilégios, diferenças econômicas na apropriação de riquezas, diferenças de lugares nos processos produtivos, diferenças culturais e linguísticas, diferenças de especialização e de competência); (2) ater-se ao objetivo das relações de poder sobre as ações dos outros (manutenção de privilégios, acumulação de benefícios, exercícios de determinada função); (3) averiguar as modalidades instrumentais do poder (as armas, os discursos, os mecanismos de controle, as disparidades econômicas, os sistemas de vigilância e fiscalização); (4) observar as formas de institucionalização do poder (os sistemas complexos, tais como o Estado, as estruturas jurídicas, os fenômenos habituais, os locais específicos dotados de regulamentos e uma hierarquia específica); (5) observar o nível de racionalização com base em determinados indicadores, tais como os que 
apontam a eficácia dos instrumentos, a certeza de resultado, os custos econômicos e políticos.

São foco de uma análise genealógica do poder as diferentes modalidades de seu exercício sobre os sujeitos - individuais ou coletivos. As condutas humanas estão em foco e a este poder de agir sobre a vida das pessoas é que Foucault chamará de biopoder.

\section{Sobre os biopoderes: do indivíduo à população}

Como visto, o biopoder é um tipo de poder exercido sobre as condutas humanas - sobre a vida, seja ela individual ou coletiva. Esta modalidade de poder do qual fala Foucault é datado e histórico. Foi a partir do século XVII que o poder organizou-se em torno da vida, constituindo-se em uma forma de governo dos homens. Em um primeiro momento, deu-se por meio da disciplina ${ }^{7}$ - foi no corpo individual, considerado como uma máquina, que o poder foi investido, uma anátomopolítica do corpo humano. E, a partir de meados do século XVIII, o objeto passou do corpo individual para a coletividade - corpo-espécie vivente -, dá-se então o nascimento daquilo que Foucault denomina biopolítica.

A disciplina, como modalidade de aplicação do poder, conjuntura uma série de técnicas de coerção investidas particularmente sobre as condutas dos indivíduos. O regime disciplinar faz com que as forças produtivas do corpo possam ser ampliadas, em termos de utilidade, ao mesmo tempo em que outras forças, como a política, são minimizadas, em termos de obediência. A disciplina fabrica corpos produtivos, fortes e aptos ao trabalho, como também submissos, obedientes corpos "dóceis" (FOUCAULT, 2011).

O biopoder, na perspectiva foucaultiana, não se limitará ao Estado. Ele está estabelecido em rede de dispositivos que transcorrem a sociedade. Serão os colégios, os quartéis, os hospitais, os hospícios, os orfanatos, os asilos, serão todos, tal como no modelo dos conventos - aparatos que nascem junto com o Estado - os lugares privilegiados para o exercício do biopoder disciplinar. A disciplina será a arte

\footnotetext{
${ }^{7}$ Cabe ressaltar que a invenção da disciplina como modalidade de poder não se deu no século XVIII. Deu-se na medida em que o poder exercido no quadro da monarquia tornou-se custoso e com pouca eficácia (CASTRO, 2009).
} 
de dispor em fila, de classificar, de controlar o tempo e o espaço, de aplicar técnicas que adestram e transformam os gestos dos indivíduos. A disciplina individualiza os corpos e imprime neles uma realidade fabricada pela representação ideológica da sociedade (FOUCAULT, 2011).

Se, por um lado, o biopoder é investido sobre o sujeito para a individuação através da disciplina, por outro, ele é propagado sobre o coletivo como forma de totalização, no caso, através da biopolítica. A biopolítica, portanto, será uma modalidade do biopoder que toma o corpo-espécie, o coletivo, como objeto de estudo e intervenção com vistas à gestão da coletividade. O controle da própria espécie terá agora a dimensão coletiva, que passa a ser uma problemática para os campos dos saberes e, consequentemente, para o exercício desta outra modalidade do biopoder.

A biopolítica ocupar-se-á dos processos biológicos que captam o homem como uma espécie e, a partir daí, possibilitar meios para a sua gestão. Lançará mão de novos saberes, como a estatística, a demografia, a medicina social. Isto, pois, ao se utilizar a descrição e quantificação da população (taxas de natalidade, mortalidade, longevidade, também criminalidade, migrações), foi possível trabalhar para o governo das populações através da gestão dos riscos, de previsões, enfim, de maneiras que visem a uma homeostase populacional (FOUCAULT, 2000; 2008b).

Como visto, essas duas formas do biopoder, a disciplina e a biopolítica, diferem-se de alguma forma. A primeira tem como objeto o corpo individual, enquanto que a segunda, o corpo coletivo; logo, a disciplina traz o poder exercido pelo adestramento do sujeito e a biopolítica investirá suas ações por meio de mecanismos estatísticos e medidas globais. A disciplina conseguirá corpos dóceis e produtivos e a biopolítica, o equilíbrio da população (FOUCAULT, 2000). Ambas as formas do exercício do biopoder irão se ocupar da vida instaurando-se normas mecanismo de contínua correção e regulação. Será a norma o elo entre a disciplina e a biopolítica.

A norma é o que pode tanto se aplicar a um corpo que se quer disciplinar quanto a uma população que se quer regulamentar. [...] A sociedade de normalização é uma sociedade em que se cruzam, conforme uma articulação ortogonal, a norma da disciplina e a norma da regulamentação. Dizer que o poder [...] incumbiu-se da vida é dizer que ele conseguiu cobrir toda a superfície que se estende do orgânico ao biológico, do corpo à população, mediante o jogo duplo das tecnologias de disciplina, de uma 
parte, e das tecnologias de regulamentação, de outra (FOUCAULT, 2000, p. 302).

Uma sociedade normalizadora, dirá Foucault (2003, p. 135), "é o efeito histórico de uma tecnologia de poder centrada na vida".

\section{Um exemplo da operacionalização da genealogia para o estudo de dispositivos do biopoder}

Tendo visto conceitos e precauções metodológicas, parte-se agora para um exemplo prático da operacionalização de uma análise genealógica de dispositivos do biopoder. Tomaremos como campo de análise o exercício da biopolítica no quadro da experimentação com seres humanos. Mais precisamente, ocuparemo-nos da Declaração de Helsinque (DH), normativa que exprime um conjunto de princípios éticos para a investigação médica com seres humanos, promulgada pela Associação Médica Mundial (AMM) em 1964, a qual, após sete processos de atualização de seus princípios, permanece como normativa atualmente endereçada à comunidade médica mundial.

A DH consiste em um documento que administra comportamentos de médicos pesquisadores - é, portanto, uma norma. E, em última análise, implica em certas formas de sujeição dos participantes de pesquisas biomédicas. Assim, é uma norma que implanta efeitos reais e efetivos ao determinar condutas - dos médicos, e ao acabar por sujeitar pessoas - os participantes do estudo.

$\mathrm{O}$ estudo dos dispositivos do biopoder partindo-se da DH encontra contexto privilegiado: trata-se de um documento vivo - é histórico e atual, visto suas constantes atualizações. Sua emergência e desenvolvimento têm lugar e tempo dados. Não se trata de uma normativa de determinado Estado, mas de uma associação; desse modo, não de orientar a pesquisa no sentido do aparelho jurídico de Estados, tampouco das ideologias que os acompanham; do contrário, possibilita uma análise ascendente do poder - permite-se abordá-lo lá onde ele se torna capilar.

A DH enuncia o saber relacionado à eticidade das pesquisas envolvendo seres humanos; saber este que se constitui como procedimento que acaba por regulamentar pesquisas médicas. A genealogia será, portanto, o caminho para a 
desconstrução de tais saberes, no caso a desconstrução de determinados princípios éticos para a pesquisa os quais foram historicamente construídos.

Dito isso, parte-se da tese de que a $\mathrm{DH}$ apresenta dispositivos de poder que legitimam intervenções biopolíticas. Neste caso, o problema a ser investigado pelo método genealógico será desvendar como princípios éticos para pesquisas envolvendo seres humanos surgiram e se desenvolveram de tal modo que se configuram como dispositivos do biopoder. Entendendo que a $\mathrm{DH}$ emana um conjunto amplo de princípios, uma delimitação deverá ser feita: deve-se analisar cada princípio em particular. Para citar exemplos: pode-se analisar a gênese e o desenvolvimento do princípio ético do uso do placebo em pesquisas clínicas como um dispositivo biopolítico; examinar o nascimento e as adequações do princípio do acesso pós-estudo, atualmente chamado de "provisões pós-ensaio", como dispositivo do biopoder; problematizar a extinção da diferenciação de princípios éticos para pesquisas terapêuticas daqueles para pesquisas não terapêuticas, e mostrar que essa extinção se configura como um dispositivo de poder biopolítico.

Agora, tendo feito o recorte, o trabalho do genealogista será de debruçar-se em bases documentais que narram a história da $\mathrm{DH}$. Ele terá ainda que localizar outras fontes de informações que contextualizem e problematizem tal história em um contexto social, econômico, político, e que tragam à tona detalhes que possam passar despercebidos, os quais poderiam ser considerados corriqueiros. Tudo isso para que seja possível a "constituição de um saber histórico das lutas e a utilização deste saber nas táticas atuais" (FOUCAULT, 2004a, p. 171).

Para o exemplo dado, será preciso analisar, como fonte principal, os documentos oficiais da Associação Médica Mundial: as atas das assembleias gerais, as minutas das sessões de conselho, os relatórios do Comitê de Ética Médica da AMM, os memorandos da AMM encaminhados às associações médicas nacionais e aqueles que recebe dessas; os documentos provenientes das consultas às organizações e das consultas públicas em geral; os drafts feitos ao longo dos processos de revisão da $\mathrm{DH}$; as versões oficiais da Declaração de Helsinque. Também, artigos e livros publicados sobre a $\mathrm{DH}$ e sobre os assuntos pesquisados (ética no uso do placebo em pesquisas clínicas, acesso pós-estudo, diferença entre princípios éticos para pesquisas terapêuticas e para não terapêuticas) devem ser localizados e problematizados. 
Em posse dos documentos, estes precisam ser organizados na perspectiva de arquivo. Segundo Foucault, não se trata, tal como na linguagem corrente, de simples conjunto de documentos guardados como memória do passado. Antes, arquivo remete ao emaranhado de condições históricas que permitiram emergir determinados enunciados, e não outros. Arquivo é o conjunto desses discursos pronunciados, que permanecem em funcionamento, transforma-se e possibilita o surgimento de outros. Não se trata de discursos ocorridos que ficaram suspensos em um determinado local e tempo (FOUCAULT, 2003). Tendo em conta a premissa do arquivo, os referidos documentos não deverão ser questionados como matéria bruta que possibilita a descrição de uma história linear, tradicional, portanto, que reconstitui a simples memória dos episódios; antes, esses documentos deverão ser questionados em conjunto, observando-se as relações entre si, ser tomados segundo sua descrição intrínseca.

Com a finalidade de compreender como determinado princípio ético expresso na $\mathrm{DH}$ se originou e se desenvolveu ao ponto de se configurar como dispositivo do biopoder, os documentos precisam ser interrogados mediante questionamentos, tais como os que seguem: (a) que elementos discursivos e não discursivos possibilitaram a existência de um determinado princípio ético (enunciado)? (b) de que modo esses enunciados (esses princípios éticos) ganharam legitimidade? Que estratégias foram usadas? Quais outros discursos deram base para sua sustentação? (c) Que forças se fizeram presentes e se constituíram como apoios para cada um dos princípios assinalados (indústria, Estado, ideologias, organizações)? (d) Como determinado princípio ético promulgado se expressa como dispositivo normativo biopolítico que envolve o governo das populações? (e) Como cada um dos princípios podem se constituir como prática de sujeição dos participantes de pesquisas?

Ainda, para a análise dos documentos na perspectiva arqueológica e genealógica, um roteiro para a leitura dos documentos foi elaborado a partir de Lopes (2012), o qual segue no Quadro 1. 


\begin{tabular}{|c|c|c|}
\hline \multirow{5}{*}{ 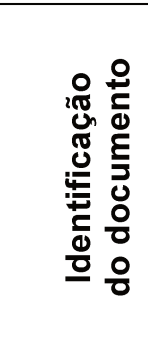 } & Título & \\
\hline & Referência & \\
\hline & Data e Local & \\
\hline & Tema Central & \\
\hline & Objetivos & \\
\hline \multirow{5}{*}{ 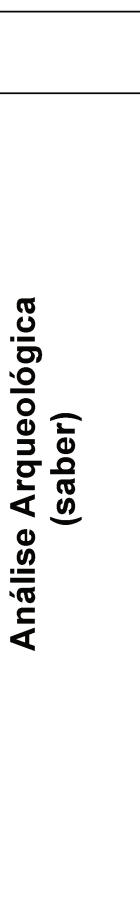 } & & $\begin{array}{l}\text { Conteúdo dos documentos/ Eixos de } \\
\text { análise/ séries enunciativas }\end{array}$ \\
\hline & $\begin{array}{l}\text { Formação dos objetos } \\
\text { A superfície primeira } \\
\text { As instâncias de delimitação } \\
\text { As grades de especificação } \\
\end{array}$ & \\
\hline & $\begin{array}{l}\text { Modalidades Enunciativas } \\
\text { Quem fala? } \\
\text { De que lugar institucional é falado? }\end{array}$ & \\
\hline & $\begin{array}{l}\text { Formação de Conceitos } \\
\text { As formas de sucessão na ordem das } \\
\text { séries enunciativas; } \\
\text { As formas de sucessão relativas aos } \\
\text { esquemas retóricos; } \\
\text { As formas de coexistência; } \\
\text { As formas de coexistência (campos de } \\
\text { concomitância e campos de memória). }\end{array}$ & \\
\hline & $\begin{array}{l}\text { Estratégias } \\
\text { Pontos de difração; } \\
\text { Economia da constelação discursiva; } \\
\text { Função exercida pelo discurso. }\end{array}$ & \\
\hline \multirow{3}{*}{ 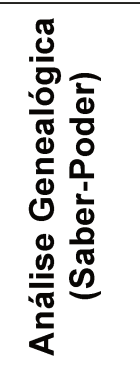 } & $\begin{array}{l}\text { Jogos biopolíticos, governo medicalizado } \\
\text { da vida - normalização biopolítica. }\end{array}$ & \\
\hline & Objetivação e subjetivação dos sujeitos. & \\
\hline & $\begin{array}{l}\text { Modos de sujeição, cristalizações de } \\
\text { relações cotidianas de poder, coerções. }\end{array}$ & \\
\hline
\end{tabular}

Quadro 1: Roteiro de Leitura arqueológica e genealógica dos documentos.

Fonte: Adaptado de Lopes, 2012.

Os documentos precisam ser lidos, questionados e organizados em arquivos, de preferência em uma perspectiva cronológica e sequencial, de forma a facilitar a compreensão da gênese e dos processos de instauração de princípios éticos expressos como instauradores de dispositivos biopolíticos.

Ainda, para melhor compreensão do contexto sócio-histórico que possibilitou a emergência de determinados enunciados, sugere-se a construção de uma linha do tempo com os eventos-chave da história, no caso específico história da ética em 
pesquisa envolvendo seres humanos. Um exemplo é vislumbrado na Figura 1, abaixo, a qual apresenta os eventos mais importantes da História da Declaração de Helsinque e da ética em pesquisa envolvendo seres humanos.

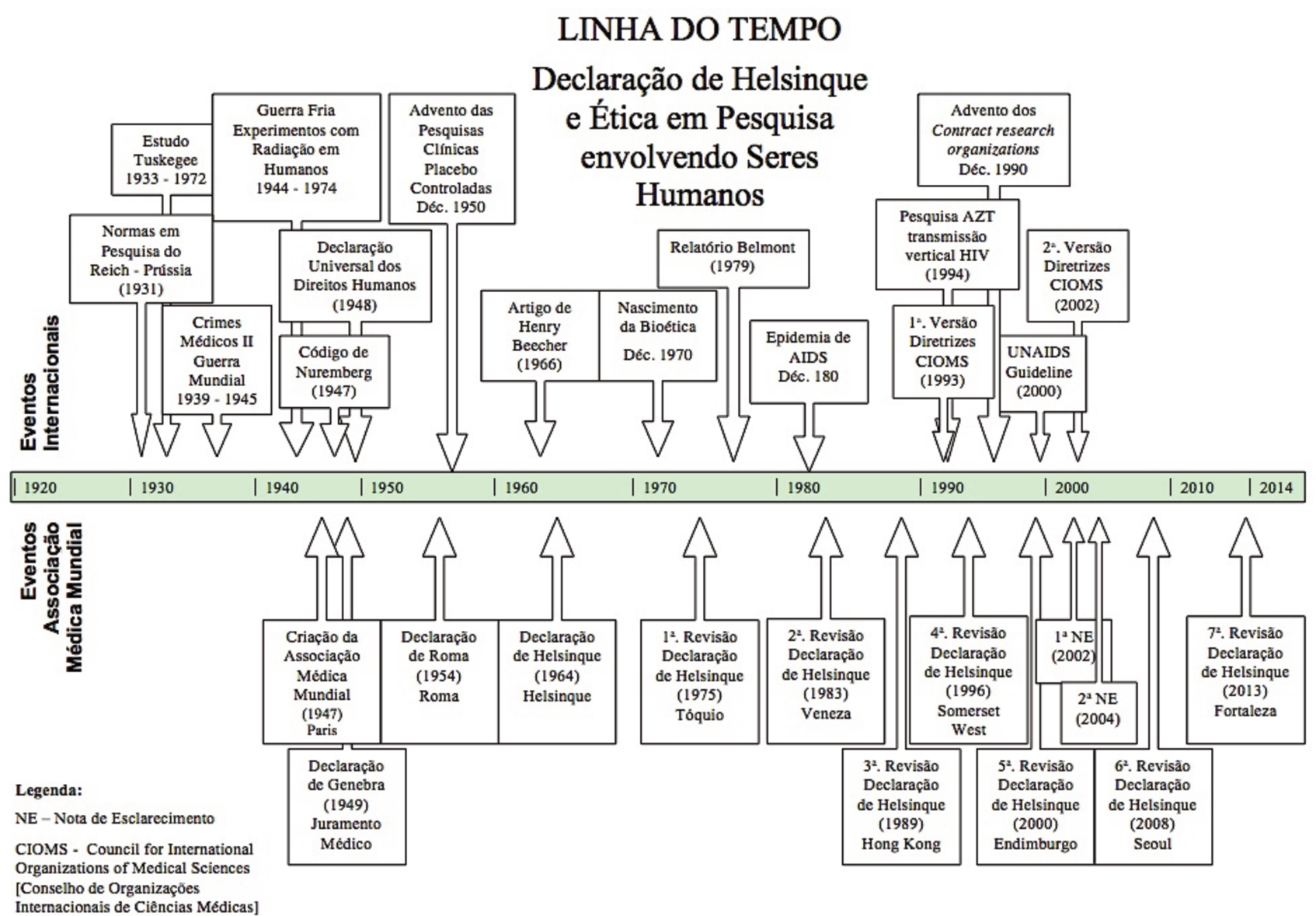

Figura 1: Linha do tempo de eventos da Declaração de Helsinque e da Ética em Pesquisa envolvendo Seres Humanos.

Fonte: elaborado pelos autores, 2014.

A linha do tempo possibilita uma melhor verificação das condições do surgimento dos enunciados, no caso do discurso da ética em pesquisa envolvendo seres humanos, bem como de suas transformações.

Por meio do exemplo dado de operacionalização da genealogia para a análise dos dispositivos do biopoder, nota-se que será possível a observação da gênese de determinado enunciado, assim como a identificação de forças, práticas discursivas e não discursivas que sustentam tais enunciados, como no exemplo, aqueles que se materializam como princípios da $\mathrm{DH}$. 


\section{Considerações Finais}

O início das obras de Foucault data da década de 1960, contemporâneo com os principais fatos que possibilitaram o surgimento da bioética. $E$, embora o nascimento da bioética esteja geralmente associado a certas pessoas e fatos do contexto estadunidense, este fato é apenas a superfície de sua origem. Para Junges (2011), o surgimento da bioética está ligado à constituição do biopoder próprio das ciências, e suas formas de subjetivação dos indivíduos. Logo, a bioética encontra nas obras de Foucault aporte teórico e metodológico profícuo.

Como visto as três fases das obras de Foucault - a da arqueologia, a da genealogia e a da ética - contribuem ao campo da bioética. Assim, "nossa reivindicação é que bioeticistas devem juntar-se aos estudiosos de outros campos e perceber que é bom pensar com Foucault" (FRANK, JONES, 2003 p. 179).

Se um dos papéis da bioética é explicitar as dinâmicas biopolíticas presentes na constituição da subjetividade humana, sobretudo atrelada àquelas decorrentes do campo das ciências da vida (JUNGES, 2011), por conseguinte, a genealogia de Foucault constitui-se de uma opção metodológica para os estudos dos campos da bioética.

Em não existindo uma obra escrita por Foucault que explicitasse os aspectos metodológicos da empreitada genealógica, especialmente na literatura bioética internacional, este ensaio contribui para o preenchimento de tal lacuna. $A$ partir dos conceitos foucaultianos apresentados, das ampliações no deslocamento da arqueologia à genealogia, dos princípios e das precauções de como empreender a genealogia como análise do exercício do poder e de um exemplo de sistematização para operacionalizar a genealogia no estudo de dispositivos do biopoder, considera-se que a genealogia é uma metodologia compatível com o campo da bioética. 


\section{Referências}

ASHCROFT, R. E. Constructing Empirical Bioethics: Foucauldian Reflections on the Empirical Turn in Bioethics Research. Health Care Analysis. V.31, I.3, p.3-13, Mar. 2003. DOI: $10.1023 / \mathrm{A}: 1025329811812$

BISHOP, J. P.; JOTTERAND, F. Bioethics as Biopolitics. Journal of Medicine and Philosophy. V.31, I.3, p.205-212, Jun. 2006 DOI: 10.1080/03605310600712760

CAPONI, S. A biopolítica da população e a experimentação com seres humanos.

Ciêncência \& Saúde Coletiva, Rio de Janeiro, v.9, n.2, Jun. 2004. DOI: 10.1590/S1413-81232004000200020.

FINKLER, M. et al . Formação profissional ética: um compromisso a partir das diretrizes curriculares?. Trab. educ. saúde (Online), Rio de Janeiro, v.8, n. 3, Nov. 2010. DOI: $10.1590 /$ S1981-77462010000300007.

FOUCAULT, M. A Arqueologia do Saber. 7 ed. Rio de Janeiro: Forense Universitária, 2007.

FOUCAULT, M. A ordem do discurso: aula inaugural no Collège de France, pronunciada em 2 de dezembro de 1970. 3. ed. São Paulo: Loyola/SC, 1996.

FOUCAULT, M. À propos de la généalogie de l'éthique : un aperçu du travail en cours » ; entretien avec H. Dreyfus et P. Rabinow. In: DREYFUS, H.; RABINOW, P. Michel Foucault : un parcours philosophique, Paris, Gallimard, 1984, p. 322-346. Disponível em: http://1libertaire.free.fr/MFoucault253.html Visitado em 15 de julho de 2014.

FOUCAULT, M. Confession of the Flesh: Recherches sur lê Systeme Pénitentiaire ao XIX Siècle. Paris: Éd. Du Seuil, 1980.

FOUCAULT, M. Ditos e Escritos, Vol. IV: estratégia poder-saber. Rio de Janeiro: Forense Universitária, 2003.

FOUCAULT, M. Do governo dos vivos. Transcrição, tradução e notas de Nildo Avelino. São Paulo: Centro Cultural Social, 2009. Disponível em: 
http://www.ccssp.org/arquivos/textos/Do\%20governo\%20dos\%20vivos.pdf Acesso em 10 de julho de 2014.

FOUCAULT, M. Em defesa da sociedade: curso no Collège de France, 1975-1976. São Paulo: Martins Fontes, 2000.

FOUCAULT, M. Genealogia e Poder. In: FOUCAULT, M.; MACHADO, R. Microfísica do poder. 19. ed. Rio de Janeiro: Graal, 2004a. p. 167-178.

FOUCAULT, M. História da Sexualidade 1: a vontade de saber. 15. ed. Rio de Janeiro: Graal, 2003.

FOUCAULT, M. História da sexualidade 3: o cuidado de si. 7. ed. Rio de Janeiro: Graal, 2002.

FOUCAULT, M. Les problèmes de la culture. Un débat Foucault-Preti» ; entretien avec G. Preti, recueilli par M. Dzieduszycki ; trad. A. Ghizzardi, II Bimestre, nos 2223, sep-déc.1972, p.1-4. Disponível em: http://1libertaire.free.fr/MFoucault157.html Acesso em 9 de julho de 2014.

FOUCAULT, M. Segurança, território, população. São Paulo: Martins Fontes, 2008a.

FOUCAULT, M. Soberania e Disciplina. In: FOUCAULT, M.; MACHADO, R. Microfísica do poder. 19. ed. Rio de Janeiro: Graal, 2004b. p.179-192.

FOUCAULT, M. Vigiar e punir: nascimento da prisão. 39. ed. Petrópolis: Vozes, 2011.

FOUCAULT, M.; MACHADO, R. Microfísica do poder. 19. ed. Rio de Janeiro: Graal, 2004.

FOUCAULT, M. Nascimento da biopolítica: curso no Collège de France (19781979). São Paulo: Martins Fontes, 2008b.

FRANK, A. W.; JONES, T. Bioethics and the Later Foucault. Journal of Medical Humanities. V.24, I.3-4, pp 179-186, Dec. 2003. DOI: $10.1023 / A: 1026014718326$ 
GIRALDO, L. F. G.; ZULUAGA, C. G. El cuidado de sí y de los otros en Foucault, principio orientador para la construcción de una bioética del cuidado. Discus.filos, Manizales, v.14, n.22, Jun. 2013. Available from <http://www.scielo.org.co/scielo.php?script=sci_arttext\&pid=S0124$61272013000100012 \&$ Ing=en\&nrm=iso>. access on 29 July 2014.

JUNGES, J. R. O nascimento da bioética e a constituição do biopoder. Acta Bioethica. Santiago, V.17, N.2, p.171-178. 2011. Nov. 201. Disponible en <http://www.scielo.cl/scielo.php?script=sci_arttext\&pid=S1726$569 \times 2011000200003 \&$ Ing=es\&nrm=iso $>$. accedido en 25 agosto 2014. http://dx.doi.org/10.4067/S1726-569X2011000200003.

JUNGES, J. R. Right to health, biopower and bioethics. Interface (Botucatu), Botucatu, v. 13, n. 29, Jun. 2009. Available from <http://www.scielo.br/scielo.php?script=sci_arttext\&pid=S1414$32832009000200004 \&$ Ing=en\&nrm=iso>. access on 29 July 2014. http://dx.doi.org/10.1590/S1414-32832009000200004.

LOPES, A. M. P. Saúde no Processo de Democratização Brasileiro: promoção da saúde, biopolíticas e práticas de si na constituição de sujeitos de saúde. 2012. 312f. Tese (doutorado) - Universidade Federal de Santa Catarina, Centro de filosofia e Ciências Humanas. Programa de Pós-Graduacão em Psicologia. Florianópolis, 2012.

LYSAUGHT, T. M. Docile Bodies: Transnational Research Ethics as Biopolitics. J Med Philos. V.34, I.4, p.384-408, Aug. 2009. Doi: 10.1093/jmp/jhp026.

MORENO, J. D. Chimera in Bioethics and Biopolitics. In: AKABAYASHI, A. The Future of Bioethics: International Dialogues. OXFORD, UK: Oxford University Press, 204. p. 380-389.

RABINOW, P.; DREYFUS, H. L. Michel Foucault: uma trajetória filosófica: para além do estruturalismo e da hermenêutica. Rio de Janeiro: Forense Universitária, 1995.

REVEL, J. Le Vocabulaire De Foucault. Paris: Ellipses Édition Marketing, 2002. Disponível em: http://www.fichier-pdf.fr/2012/10/19/le-vocabulaire-de-foucault/ Visitado em 15 de julho de 2014. 
ROMMETVEIT, K. Bioethics, Biopower and the Post-Genomic Challenge. In: GUNNING, J; SøREN, H.; KENWAY, I. Ethics, law and society. Farnham, England: Ashgate Publishing Ltda, 2009. p. 165-186.

TREMAIN, S. The Biopolitics of Bioethics and Disability. Journal of Bioethical Inquiry. V.5, I.2-3, p.101-106, Jun. 2008.

Artigo:

Recebido em: $25 / 08 / 2014$

Aceito em: 4/12/2014 